
\title{
B Pesearch S Surare \\ Spinopelvic sagittal imbalance is risky for development of proximal instrumented fracture after posterior instrumentation.
}

Jen-Chung Liao ( $\sim$ jcl1265@adm.cgmh.org.tw )

Chang Gung Memorial Hospital

Wen-Jer Chen

Chang Gung Memorial Hospital

\section{Research Article}

Keywords: proximal junctional failure, spinopelvic sagittal imbalance, posterior instrumentation

Posted Date: March 3rd, 2021

DOI: https://doi.org/10.21203/rs.3.rs-253715/v1

License: (c) (i) This work is licensed under a Creative Commons Attribution 4.0 International License.

Read Full License 


\section{Abstract \\ Backgrounds:}

Postoperative fracture of the upper instrumented vertebrae (UIV) is thought to be as fracture type of proximal junctional failure (PJF), which usually needs revision surgery for salvage. The purpose of this study was to investigate the influences of spinopelvic parameters, such as the pelvic incidence (PI) angles, sacral slope (SS) angles, and pelvic tilt (PT), sagittal vertical axis (SVA), and proximal local kyphosis (PLK) angle on the development of fracture type of proximal junctional failure after posterior instrumentation.

\section{Methods}

This was a retrospective 1:3 matched case-control cohort study: 24 patients in the study group and 72 patients in the control group. The weighted Charlson Comorbidity Index $(\mathrm{CCl})$ and bone mineral density (BMD) with T score were recorded. In addition to spinopelvic parameters, PI-LL and spinopelvic realignment score were calculated.

\section{Results}

More comorbidities $(\mathrm{CCl}, \mathrm{p}=0.002)$, poorer bone density ( $T$ score, $p=0.001)$ were noted in the study group. Before surgery, the study group had significantly lower LL $(p=0.046), S S(p=0.043)$, and significantly higher PLK $(p<0.001)$, PT $(p=0.044)$ than the control group. Postoperatively, the study group had significantly higher PLK $(p<0.001)$ and lower LL $(p=0.031)$ than the control group; the degree of PI-LL ( $p=0.007)$ remained significantly higher in the study group. Both preoperative $(p=0.026)$ and postoperative $(p=0.045)$ spinopelvic realignment scores was worse in the study goup.

\section{Conclusions}

Preoperative and postoperative lower LL/spinopelvic realignment score, and higher PLK/PI-LL were significantly associated with instrumented fracture at upper instrumented vertebrae. An appropriate LL and a lower PLK should be obtained at surgery to prevent the development of instrumented fracture.

\section{Introduction}

Proximal instrumented fracture means fracture developed at the uppermost instrumented vertebrae (UIV) after posterior instrumentation. Proximal junctional failure (PJF) after instrumented spinal fusion is a well-known complication that makes clinical outcomes worse and usually needs revision surgery. The etiologies of PJF include a few categories: degenerative process, hardware loosening, or fracture induced. Proximal junctional kyphosis over $20^{\circ}$ with symptoms by disc degeneration at upper segment is thought 
as degeneration type of PJF; a fracture at UIV or UIV + 1 is considered to be fracture type of PJF [1]. Therefore, proximal instrumented fracture is a part of PJF. Degenerative process of PJF usually takes years to develop, but fracture type of PJF generally happens within few months after primary index surgery, which makes patients feel more frustrated because they need to undergo a revision surgery within a short period of time.

Spinopelvic malalignment is associated with clinical outcomes of lumbar arthrodesis, and also contributes to the development of adjacent segment degeneration after instrumentation [2-4]. Older age, osteoporosis, UIV level at the thoracolumbar junction and greater preoperative sagittal vertical axis (SVA) were identified to be risk factors of PJF [5]. Spinopelvic parameters such as sacral slope (SS), pelvic tilting (PT), and pelvic incidence (PI) has been recognized to affect overall global sagittal balance [6]. Little literatures focused on the relationship between spinopelvic alignment and proximal instrumented fracture. We hypothesized that spinopelvic malalignment contributes to the development of proximal instrumented fracture. To exclude factors by surgical levels, age, and sex in the current study, the patients were limited to 1:3 matched case-control cohorts using the same instrumentation and the same fusion techniques. The purpose of this study was to clarify the relationship between spinopelvic radiographic parameters and proximal instrumented fracture after posterior thoracolumbar or lumbar instrumented fusion.

\section{Materials And Methods}

This study (No. 202000340B0) was approval from the institutional review board of our hospital. All participates were received and signed informed consent. Patients underwent posterior instrumented fusion for thoracolumbar or lumbar diseases between January 2007 and December 2017 were reviewed. Those patients who had undergone revision surgery for symptomatic instrumented fracture at UIV were enrolled as the study group (Figure 1). As this was a 1:3 matched case control study, seventy-two patients were selected as a control group (Figure 2). We searched for these patients who matched the study group by main diagnosis with same surgical levels by reviewing medical records form our spinal surgery database. Same gender and similar age were another criterion for selecting. The preoperative medical condition of these patients was reviewed using the weighted Charlson Comorbidity Index (CCI) [7] and the American Society of Anesthesiologists (ASA) physical status classification [8]. Demographic data including age, sex, body mass index (BMI), bone mineral density (BMD) with T score, and fused segments of all study subjects were collected from medical records. Clinical outcomes were evaluated using the visual analogue scale (VAS) of leg and back pain [9] and the Oswestry Disability Index [10. The radiographic parameters including the lumbar lordosis (LL), sacral slope (SS), pelvic tilt (PT), pelvic incidence (PI), proximal local kyphosis (PLK), coronal scoliosis (CS), and sagittal vertical axis (SVA). LL angle was measured using Cobb method of upper endplate of L1-S1; SS angle was measured the angle between the sacral endplate and a horizontal line; PT angle was measured by the line through midpoint of sacral plate and midpoint of femoral heads axis, and the vertical line; PI angle measured by the line through midpoint of sacral line and midpoint of femoral heads axis, and the line vertical to sacral plate; PLK angle measured using Cobb method of upper endplate of UIV+1 and lower endplate of UIV 
presenting in kyphotic angle; CS angle was measured the maximal scoliosis angle on coronal plain radiographs; SVA was measured as the distance between the C-7 plumb line and the superior posterior corner of the S-1 vertebral body in the lateral radiograph. The achievement of a successful harmony of spinopelvic realignment had been mentioned by Schwab et al and score for spinopelvic realignment achievement were recorded [11]. The ideal realignment objectives in the sagittal plane included SVA < $50 \mathrm{~mm}, \mathrm{PT}<20^{\circ}$ and $\mathrm{LL}=\mathrm{PI} \pm 10^{\circ}$. The patient with $\mathrm{PT}<20^{\circ}$ would get 1 point, if not, get nothing. In the same way, the patient with $L L=P I \pm 10^{\circ}$, would get 1 point, if not, get nothing; the patient with $S V A<50$ $\mathrm{mm}$, would get 1 point, if not, get nothing. Thus, the total score ranges from 0 to 3 . The higher score represents the better achievement of spinopelvic harmony.

Statistical analysis

Chi-square test and Fisher's exact test were used for categorical variables. Mann-Whitney $U$ test was used for continuous variables. A value of $p<0.05$ was considered statistically significant.

\section{Results}

The study group contained 24 cases, which included 4 male and 20 female with a mean age of 71 yearold at surgery. The main diagnosis for surgery were degenerative lumbar spondylolisthesis, degenerative lumbar scoliosis, thoracolumbar or lumbar kyphoscoliosis, adjacent instability with failed back surgery syndrome, thoracolumbar burst fracture. The average surgical segments were 4.3: T10-L5 (1), T11-L5 (1), T12-L5 (3), L1-L5 (3), L2-L5 (4), T11-S1 (1), L1-S1 (4), L2-S1 (3), and L3-S1 (4). The control group had 72 patients with a similar age (70 years old) at surgery, the same gender ratio (M/F = 12: 60$)$, and an equal surgical levels ( 4.3 segments). The ASA classification ( $2.87 \pm 0.56$ vs $2.63 \pm 0.64, p=0.733$ ) and BMI ( $25.99 \pm 3.77$ vs $26.56 \pm 3.51, p=0.796)$ were also similar in both groups. But the study group already had more comorbidities (CCl: $1.75 \pm 0.90$ vs $1.22 \pm 0.61, p=0.002$ ), poorer bone density ( $\mathrm{T}$ score: $-3.41 \pm 1.12$ vs $-2.46 \pm 0.42, p<0.001)$ than the control group.

\section{Radiographic parameters in the study group}

Preoperative radiographic parameters including PLK, LL, SS, PT, PI, SVA, and CS were $2.98^{\circ} \pm 9.23^{\circ}$, $22.85^{\circ} \pm 17.15^{\circ}, 22.69^{\circ} \pm 10.69^{\circ}, 27.86^{\circ} \pm 11.62^{\circ}, 50.54^{\circ} \pm 9.96^{\circ}, 68.12^{\circ} \pm 29.13^{\circ}$, and $6.73^{\circ} \pm 6.54$

$\circ$. Immediately after surgery, these parameters became to $5.33^{\circ} \pm 8.51^{\circ}, 25.52^{\circ} \pm 11.71^{\circ}, 26.68^{\circ} \pm 11.45^{\circ}$, $24.93^{\circ} \pm 10.13^{\circ}, 51.23^{\circ} \pm 11.47^{\circ}, 50.17^{\circ} \pm 18.11^{\circ}$, and $5.06^{\circ} \pm 5.54^{\circ}$, separately. SS got a statistically significant increase $(p=0.042)$; SVA $(p<0.001)$ and CS $(p<0.001)$ had statistically significant decrease. Preoperative PI-LL was $27.69^{\circ} \pm 17.25^{\circ}$, which was corrected to $25.71^{\circ} \pm 12.83^{\circ}$ without significant difference $(p=0.522)$. However, spinopelvic realignment score achieved a significant change $(0.73 \rightarrow 1.30$, $p<0.001$ ) by surgery. Table 1 summarized this paragraph.

\section{Radiographic parameters in the control group}


Preoperative radiographic parameters including PLK, LL, SS, PT, PI, SVA, and CS were $-9.20^{\circ} \pm 12.89^{\circ}$, $31.66^{\circ} \pm 15.11^{\circ}, 28.34^{\circ} \pm 12.66^{\circ}, 23.39^{\circ} \pm 9.67^{\circ}, 51.73^{\circ} \pm 12.09^{\circ}, 50.91^{\circ} \pm 16.22^{\circ}$, and $8.76^{\circ} \pm 13.66$ $\circ$. Immediately after surgery, these parameters became to $-9.13^{\circ} \pm 13.97^{\circ}, 33.02^{\circ} \pm 14.73^{\circ}, 28.88^{\circ} \pm$ $11.05^{\circ}, 21.46^{\circ} \pm 7.51^{\circ}, 50.34^{\circ} \pm 11.39^{\circ}, 40.32^{\circ} \pm 12.56^{\circ}$, and $4.26 \pm 3.54$, separately. SVA $(p<0.001)$ and CS $(p=0.003)$ became significantly significant decrease immediately after surgery. Preoperative PI-LL was $20.07^{\circ} \pm 11.53^{\circ}$, which was corrected to $17.32^{\circ} \pm 12.64^{\circ}$ after surgery with significant improvement $(p=0.011)$. Spinopelvic realignment score also demonstrated a significant change $(1.22->1.59, p<0.001)$ by surgery. Table 2 summarized this paragraph.

\section{Comparisons between the study and the control group}

\section{Preoperative radiographic parameters}

The study group had significantly lower LL $\left(22.85^{\circ} \pm 17.15^{\circ}\right.$ vs $\left.31.66^{\circ} \pm 15.10^{\circ}, p=0.046\right)$, SS $\left(22.69^{\circ} \pm\right.$ $10.69^{\circ}$ vs $\left.28.34^{\circ} \pm 12.66^{\circ}, p=0.043\right)$, and significantly higher PLK $\left(2.98^{\circ} \pm 9.23^{\circ}\right.$ vs $-9.20^{\circ} \pm 12.89^{\circ}, p$ $<0.001)$, PT $\left(28.42^{\circ} \pm 12.50^{\circ}\right.$ vs $\left.23.39^{\circ} \pm 9.67^{\circ}, p=0.044\right)$, SVA $\left(68.12^{\circ} \pm 9.13^{\circ}\right.$ vs $50.91^{\circ} \pm 6.22^{\circ}, p=$ $0.017)$ than the control group had. The average PI-LL was significantly higher in the study group $\left(27.69^{\circ}\right.$ $\pm 17.25^{\circ}$ vs $20.07^{\circ} \pm 11.53^{\circ}, p=0.042$ ). A significantly lower score for spinopelvic realignment achievement $(0.73 \pm 0.98$ vs $1.22 \pm 0.96, p=0.026)$ were also found in the study group preoperatively. Other preoperative parameters including CS, PI were also not found to be significantly different between two groups. These data were summarized in Table 3.

\section{Postoperative radiographic parameters}

The study group had significant lower $\operatorname{LL}\left(25.52^{\circ} \pm 11.71^{\circ}\right.$ vs $\left.33.02^{\circ} \pm 14.73^{\circ}, p=0.031\right)$, significantly higher PLK $\left(5.33^{\circ} \pm 8.51^{\circ}\right.$ vs $\left.-9.13^{\circ} \pm 13.97^{\circ}, p<0.001\right)$ and SVA $\left(50.17^{\circ} \pm 18.11^{\circ}\right.$ vs $40.32^{\circ} \pm 12.56^{\circ}$, $\mathrm{p}=0.049$ ) than the control group had. In terms of PI-LL, both groups had a statistically significant difference $\left(25.71^{\circ} \pm 12.83^{\circ}\right.$ vs $\left.17.32^{\circ} \pm 12.64^{\circ}, p=0.007\right)$. The Postoperative spinopelvic realignment achievement score also had a significant difference between two group $(p=0.045)$. Postoperative PT $>20$ degree was observed in 14 of 24 patients (58\%) in the study group and in 45 of 75 patients (63\%) in the control group $(p=0.716)$. No significant differences were also found in other postoperative parameters, such as PT, PI, SS, and CS. Table 4 demonstrated this comparison.

\section{Comparison of clinical outcomes between groups}

Before surgery, ODI score $(53.95 \% \pm 20.60 \%$ vs $50.30 \% \pm 17.87 \%, p=0.406)$, VAS of leg pain $(6.33 \pm 1.94$ vs $6.01 \pm 2.49, p=0.570)$, and VAS of back pain (7.04 \pm 2.21 vs $6.40 \pm 2.40, p=0.254)$ were similar between two groups. Although both groups got improvement by surgery in ODI and VAS, the control group had significant better scores in both ODI $(32.17 \% \pm 12.21 \%$ vs $20.90 \% \pm 17.94 \%, p<0.001)$ and VAS of back pain $(5.63 \pm 5.15$ vs $2.42 \pm 2.33, p<0.001)$ at the latest follow. Table 5 summarized demographic and clinical data. 


\section{Discussion}

The incidence of PJF after surgery for patients with adult spinal deformities might range from $2 \%$ to $20 \%$, and this wide range can be attributed mostly to the heterogeneity of the study populations, surgical method, and the difference in the definition of PJF [12]. Yagi et al. observed 113 patients underwent surgical correction for their adult spinal deformities by method of propensity-matched comparison and concluded that low bone-mineral density is a significant risk factor to develop PJF [13]. Park et al. studied 63 cases underwent posterior instrumented fusion with their UIV at thoracolumbar junction and concluded that older than 70 years old and osteoporosis would increase incidence of PJF [14]. Because primary osteoporosis is positively related to age, it is easy to understand that patient with older age had higher incidence to develop PJF. In the current study, although the mean age surgery was similar, the study group had a significantly lower BMD than that in the control group, which explained that osteoporosis was really positively related to development of PJF. Furthermore, higher CCI leaded to lower BMD was found in the present study. The same phenomenon was also demonstrated by Bartels et al.: higher $\mathrm{CCl}$ and lower BMD were positively correlated at the same age [15].

Scheer et al. suggested that the UIV at T8 or below level would increase the risk to develop PJF [16]. Similarly, Shufflebarger et al. recommended that fusion should stop at T10 or above level but not at thoracolumbar junction in adult spinal deformity surgery to decrease the incidence of PJF [17]. In contrast, some studies did not support that the UIV at thoracolumbar junction was a risk factor to develop PJF $[18,19]$. In the current study, of 24 cases of the study group, 19 patients' UIV located at T11-L2; the other five cases' UIV were at T10 and L3. But we could not conclude whether the UIV at TLJ was risky to develop PJK by our research, because these cases did not have the same diagnosis to determine their surgical level. In our practice, the selection of UIV usually chooses neutral and stable vertebrae on coronal plane, and the adjacent segment on the sagittal plane is healthy without obvious disc degeneration, and most cases' UIV in our study located at TLJ. However, another three times matched patients at TLJ in the control group were not found to be developed PJF, we would not suggest that every case should be always instrumented fusion to mid-thoracic level to prevent PJF.

Spinopelvic parameters have been studied in patients with adjacent segment disease after lumbar or thoracolumbar fusion. The main spinopelvic parameters include LL, SL, PT, and PI. Significant less LL was thought to be a risk factor to accelerate adjacent segment degeneration by Djursovic et al. [20]. In contrast, Lai et al found that less LL did not increase the incidence of adjacent segment disease after lumbar fusion [21]. In the current study, LL of the control group was significantly lordotic than that of the study group in both preoperative and postoperative radiographs. However, it was still difficult to determine the appropriate LL for individual person to prevent PJF. A lower PI has been indicated a risk factor to generate adjacent segment degeneration [22]. But there was no difference in PI between both groups in our study; we could not conclude the efficacy of PI on the development of PJF. Schwab et al. first described the importance of PI-LL mismatch on the development of adjacent segment degeneration [23]. Generally, PI minus LL less than 10 degrees is believed to be ideal. Yagi et al. Smith et al. all confirmed larger PI-LL mismatch leaded to PJF $[1,13]$. Yang et al. concluded that a larger differences in PI- 
LL mismatch by surgical correction could decrease risk of PJF [24]. Similarly, we also found the PI-LL of the control group was lower than that of the study group, which were statistically significant differences in both preoperative and postoperative radiographs. Because each patient's PI will not be changed by surgery, therefore, it is necessary to correct LL to reduce PI-LL mismatch.

In this study, the authors found larger proximally segmental local kyphosis angle resulted in the development of fracture type of PJF in both preoperative (the control group: $-9.20^{\circ}$, the study group: 2.98 $\circ, p<0.001$ ) and postoperative (the control group: $-9.13^{\circ}$, the study group: $5.3^{\circ}, p<0.001$ ) radiographs. Generally, segmental angle at TLJ should be $0^{\circ}$ in normal alignment. When proximal segmental angle becomes kyphotic, increase in the moment force of body weight will apply to the UIV. Under condition of osteoporosis, this increased force might induce fracture at UIV. Therefore, extending a few more segments of instrumentation proximally or cement augmentation at UIV might be considered when facing proximal segment kyphosis of planned UIV. In addition, some surgeon proposed additional surgical techniques to prevent junctional problems after instrumented fusion. Viswanathan et al. proposed a hybrid method with combining pedicle screw-rod construct and sub-laminar banding could provide biomechanical advantages to prevent proximal junctional stress [25]. Rodriguez-Fontan et al. proposed another easier method which used Mersilene tape to stabilize the spinal process between UIV and UIV +1 or 2 to achieve prevention of PJK [26]. However, these two methods had been clinically approved their efficacy to prevent the development of PJF.

Indeed, this study still had some limitations. First, this was a retrospective study, therefore, the patients were subjective to inconsistence in surgeon's experiences in selecting UIV level. Second, the number of the study group was still small, although 24 cases with of developed instrumented fracture were relatively larger in a series when comparing to previous literatures. Third, is was not possible to analyze all risk factors for PJF that were previously reported. Fourth, no case of UIV at mid-thoracic or upper thoracic was included in this study. Further prospective longitudinal studies are needed to identify the proper surgical method and selecting criteria for patients having a degenerative lumbar or thoracolumbar spine with spinopelvic imbalance.

\section{Conclusions}

Pre- and postoperative lower LL, and higher PI-LL/PLK were also significantly associated with development of proximal instrumented fracture. Therefore, obtaining appropriate LL and correcting PLK should be done at surgery to improve spinopelvic sagittal imbalance. The results suggest that the achivement of appropriate LL and PI-LL prevents proximal instrumented fracture after posterior instrumented fusion.

\section{Declarations}

\section{-Ethics approval}


This study was performed after obtaining approval from the institutional review board of Chang Gung Memorial Hospital (No. 202000340B0). All methods were performed in accordance with Declaration of Helsinki.

\section{-Consent to participate}

All participates were received and signed informed consent.

\section{-Consent for publication}

Not applicable

\section{-Availability of data and materials.}

All the necessary information is contained in the manuscript. The datasets used and/or analyzed during the current study are available from the corresponding author on reasonable request.

\section{-Competing interests}

The authors have declared that there are no competing interests.

\section{-Funding}

This article did not receive any funding.

\section{-Authors' contributions}

Liao JC designed the study, collected the data, wrote the manuscript, and participated in revising the manuscript. Chen WJ designed the study and also participated in revising the manuscript.

\section{-Acknowledgements}

Not applicable

\section{Abbreviations}

UIV: upper instrumented vertebrae, PJF: proximal junctional failure, PI: pelvic incidence, SS: sacral slope, PT: pelvic tilt, SVA: sagittal vertical axis, PLK: proximal local kyphosis, CCl: Charlson Comorbidity Index, BMD: bone mineral density.

\section{References}

1. Smith MW, Annis P, Lawrence BD, Daubs MD, Brodke DS.Acute proximal junctional failure in patients with preoperative sagittal imbalance. Spine J. 2015;15(10):2142-8. doi: 10.1016/j.spinee.2015.05.028. 
2. Le Huec JC, Faundez A, Dominguez D, Hoffmeyer P, Aunoble S. Evidence showing the relationship between sagittal balance and clinical outcomes in surgical treatment of degenerative spinal diseases: a literature review. Int Orthop. 2015;39(1):87-95. doi: 10.1007/s00264-014-2516-6.

3. Faldini C, Di Martino A, Perna F, Martikos K, Greggi T, Giannini S. Changes in spino-pelvic alignment after surgical treatment of high-grade isthmic spondylolisthesis by a posterior approach: a report of 41 cases. Eur Spine J. 2014;23 Suppl 6:714-9. doi: 10.1007/s00586-014-3552-z.

4. Matsumoto T, Okuda S, Maeno T, Yamashita T, Yamasaki R, Sugiura T, Iwasaki M. Spinopelvic sagittal imbalance as a risk factor for adjacent-segment disease after single-segment posterior lumbar interbody fusion. J Neurosurg Spine. 2017;26(4):435-440. doi: 10.3171/2016.9.

5. Nguyen NL, Kong CY, Hart RA. Proximal junctional kyphosis and failure-diagnosis, prevention, and treatment. Curr Rev Musculoskelet Med. 2016;9(3):299-308. doi: 10.1007/s12178-016-9353-8. Review.

6. Schwab F, Lafage V, Patel A, Farcy JP. Sagittal plane considerations and the pelvis in the adult patient. Spine. 2009;34(17):1828-33. doi: 10.1097/BRS.0b013e3181a13c08.

7. Charlson ME, Pompei P, Ales KL, MacKenzie CR. A new method of classifying prognostic comorbidity in longitudinal studies: development and validation. J Chronic Dis 1987;40:373-83.

8. Sankar A, Johnson SR, Beattie WS, Tait G, Wijeysundera N. Reliability of the American Society of Anesthesiologists Physical Status scale in clinical practice. Br J Anaesth.2014;113:424-32.

9. Burkus JK, Gornet MF, Schuler TC, Kleeman TJ, Zdeblick TA. Six-year outcomes of anterior lumbar interbody arthrodesis with use of interbody fusion cages and recombinant human bone morphogenetic protein-2. J Bone Joint Surg Am. 2009;91:1181-9.

10. Fairbank JC, Couper J, Davies JB, O'Brien JP. The Oswestry low back pain disability questionnaire. Physiotherapy. 1980;66:271-3.

11. Schwab F, Patel A, Ungar B, Farcy JP, Lafage V. Adult spinal deformity- postoperative standing imbalance: how much can you tolerate? An overview of key parameters in assessing alignment and planning corrective surgery. Spine.2010;35(25):2224-31. doi: 10.1097/BRS.0b013e3181 ee6bd4

12. Yagi M, Fujita N, Okada E, Tsuji O, Nagoshi N, Asazuma T, Ishii K, Nakamura M, Matsumoto M, Watanabe K. Fine-tuning the Predictive Model for Proximal Junctional Failure in Surgically Treated Patients With Adult Spinal Deformity. Spine. 2018;43(11):767-773. doi:

10.1097/BRS.0000000000002415.

13. Yagi M, Fujita N, Tsuji O, Nagoshi N, Asazuma T, Ishii K, Nakamura M, Matsumoto M, Watanabe K. Low Bone-Mineral Density Is a Significant Risk for Proximal Junctional Failure After Surgical Correction of Adult Spinal Deformity: A Propensity Score-Matched Analysis. Spine. 2018;43(7):485-491. doi: 10.1097/BRS.0000000000002355. 
14. Park SJ, Lee CS, Park JS, Lee KJ. Should Thoracolumbar Junction be always Avoided as Upper Instrumented Vertebra in Long Instrumented Fusion for Adult Spinal Deformity?: Risk Factor Analysis for Proximal Junctional Failure. Spine 2019 Dec 10. doi: 10.1097/BRS.0000000000003364.

15. Bartels S, Gjertsen JE, Frihagen F, Rogmark C, Utvåg SE. Low Bone Density and High Morbidity in Patients Between 55 and 70 Years With Displaced Femoral Neck Fractures: A Case-Control Study of 50 Patients vs 150 Normal Controls. BMC Musculoskelet Disord. 2019 Aug 14;20(1):371. doi: 10.1186/s12891-019-2732-8.

16. Scheer JK, Lafage V, Smith JS, Deviren V, Hostin R, McCarthy IM, Mundis GM, Burton DC, Klineberg E, Gupta M, Kebaish K, Shaffrey Cl, Bess S, Schwab F, Ames CP; International Spine Study Group (ISSG). Maintenance of radiographic correction at 2 years following lumbar pedicle subtraction osteotomy is superior with upper thoracic compared with thoracolumbar junction upper instrumented vertebra. Eur Spine J. 2015;24 Suppl 1:S121-30. doi: 10.1007/s00586-014-3391-y.

17. Shufflebarger H, Suk SI, Mardjetko S. Debate: determining the upper instrumented vertebra in the management of adult degenerative scoliosis: stopping at T10 versus L1. Spine. 2006;31(19 Suppl):S18594.

18. Cho KJ, Suk SI, Park SR, Kim JH, Jung JH. Selection of proximal fusion level for adult degenerative lumbar scoliosis. Eur Spine J. 2013;22(2):394-401. doi: 10.1007/s00586-012-2527-1.

19. Kim YJ, Lenke LG, Bridwell KH, Kim J, Cho SK, Cheh G, Yoon J. Proximal junctional kyphosis in adolescent idiopathic scoliosis after 3 different types of posterior segmental spinal instrumentation and fusions: incidence and risk factor analysis of 410 cases. Spine. 2007;32(24):2731-8.

20. Djurasovic MO, Carreon LY, Glassman SD, Dimar JR 2nd, Puno RM, Johnson JR. Sagittal alignment as a risk factor for adjacent level degeneration: a case-control study. Orthopedics. 2008;31(6):546.

21. Lai PL, Chen LH, Niu CC, Chen WJ. Effect of postoperative lumbar sagittal alignment on the development of adjacentinstability. J Spinal Disord Tech. $2004 ; 17(5): 353-7$.

22. Imagama S, Ando K, Kobayashi K, Machino M, Tanaka S, Morozumi M, Kanbara S, Ito S, Inoue T, Seki T, Ishizuka S, Nakashima H, Ishiguro N, Hasegawa Y. Impact of pelvic incidence on lumbar osteophyte formation and disc degeneration in middle-aged and elderly people in a prospective cross-sectional cohort. Eur Spine J. 2020 Mar 4. doi: 10.1007/s00586-019-06204-w. [Epub ahead of print]

23. Schwab FJ, Blondel B, Bess S, Hostin R, Shaffrey Cl, Smith JS, Boachie-Adjei O, Burton DC, Akbarnia BA, Mundis GM, Ames CP, Kebaish K, Hart RA, Farcy JP, Lafage V; International Spine Study Group (ISSG). Radiographical spinopelvic parameters and disability in the setting of adult spinal deformity: a prospective multicenter analysis. Spine. 2013;38(13):E803-12. doi: 10.1097/BRS.0b013e318292b7b9. 
24. Yang J, Khalifé M, Lafage R, Kim HJ, Smith J, Shaffrey Cl, Burton DC, Ames CP, Mundis GM Jr, Hostin R, Bess S, Klineberg EO, Hart RAA, Schwab FJ, Lafage V; International Spine Study Group (ISSG). What Factors Predict the Risk of Proximal Junctional Failure in the Long Term, Demographic, Surgical, or Radiographic?: Results From a Time-dependent ROC Curve. Spine. 2019;44(11):777-784. doi: 10.1097/BRS.0000000000002955.

25. Viswanathan VK, Ganguly R, Minnema AJ, DeVries Watson NA, Grosland NM, Fredericks DC, Grossbach AJ, Viljoen SV, Farhadi HF. Biomechanical assessment of proximal junctional semi-rigid fixation in long-segment thoracolumbar constructs. J Neurosurg Spine. 2018;30(2):184-192. doi: 10.3171/2018.7.SPINE18136.

26. Rodriguez-Fontan F, Reeves BJ, Noshchenko A, Ou-Yang D, Kleck CJ, Cain C, Burger-Van der Walt E, Patel VV. Strap stabilization for proximal junctional kyphosis prevention in instrumented posterior spinal fusion. Eur Spine J. 2020 Jan 14. doi: 10.1007/s00586-020-06291-0. [Epub ahead of print]

\section{Tables}

Table 1 Radiographic Parameters in the Study Group: Preoperative versus Postoperative

\begin{tabular}{lccc} 
Parameter & Preoperative & Postoperative & P values \\
\hline PLK & $2.98 \pm 9.23$ & $5.33 \pm 8.51$ & 0.089 \\
LL & $22.85 \pm 17.15$ & $25.52 \pm 11.71$ & 0.351 \\
SS & $22.69 \pm 10.69$ & $26.68 \pm 11.45$ & 0.042 \\
PT & $27.86 \pm 11.62$ & $24.93 \pm 10.13$ & 0.066 \\
PI & $50.54 \pm 9.96$ & $51.23 \pm 11.47$ & 0.608 \\
PI-LL & $27.69 \pm 17.25$ & $25.71 \pm 12.83$ & 0.522 \\
SVA & $68.12 \pm 29.13$ & $50.17 \pm 18.11$ & $<0.001$ \\
CS & $6.73 \pm 6.54$ & $5.06 \pm 5.54$ & 0.307 \\
Spinopelvic realignment score & $0.73 \pm 0.98$ & $1.13 \pm 0.89$ & $<0.001$
\end{tabular}

$\mathrm{PLK}=$ proximal local kyphosis; $\mathrm{LL}=$ lumbar lordosis; $\mathrm{SS}=$ sacral slope; $\mathrm{PT}=$ pelvic tilting; $\mathrm{PI}=$ pelvic incidence; $\mathrm{SVA}=$ sagittal vertical axis; $\mathrm{CS}=$ cobb's scoliosis 
Table 2 Radiographic Parameters in the Control Group: Preoperative versus Postoperative

\begin{tabular}{lccc}
\hline Parameter & Preoperative & Postoperative & P values \\
\hline PLK & $-9.20 \pm 12.89$ & $-9.13 \pm 13.97$ & 0.483 \\
LL & $31.66 \pm 15.11$ & $33.02 \pm 14.73$ & 0.190 \\
SS & $28.34 \pm 12.66$ & $28.88 \pm 11.05$ & 0.517 \\
PT & $23.39 \pm 9.67$ & $21.46 \pm 7.51$ & 0.132 \\
PI & $51.73 \pm 12.09$ & $50.34 \pm 11.39$ & 0.711 \\
PI-LL & $20.07 \pm 11.53$ & $17.32 \pm 12.64$ & 0.111 \\
SVA & $50.91 \pm 16.22$ & $40.32 \pm 12.56$ & $<0.001$ \\
CS & $8.76 \pm 13.66$ & $4.26 \pm 3.54$ & 0.003 \\
Spinopelvic realignment score & $1.22 \pm 0.96$ & $1.59 \pm 0.87$ & $<0.001$
\end{tabular}

PLK= proximal local kyphosis; $\mathrm{LL}=$ lumbar lordosis; $\mathrm{SS}=$ sacral slope; $\mathrm{PT}=$ pelvic tilting; $\mathrm{PI}=$ pelvic incidence; $\mathrm{SVA}=$ sagittal vertical axis; $\mathrm{CS}=$ cobb's scoliosis

Table 3 Comparisons of preoperative radiographic parameters between two groups

\begin{tabular}{lccc} 
Parameter & Study group & Control group & P values \\
\hline PLK & $2.98 \pm 9.23$ & $-9.20 \pm 12.89$ & $<0.001$ \\
LL & $22.85 \pm 17.15$ & $31.66 \pm 15.11$ & 0.046 \\
SS & $22.69 \pm 10.69$ & $28.34 \pm 12.66$ & 0.063 \\
PT & $27.86 \pm 11.62$ & $23.39 \pm 9.67$ & 0.063 \\
PI & $50.54 \pm 9.96$ & $51.73 \pm 12.09$ & 0.829 \\
PI-LL & $27.69 \pm 17.25$ & $20.07 \pm 11.53$ & 0.042 \\
SVA & $68.12 \pm 29.13$ & $50.91 \pm 16.22$ & 0.017 \\
CS & $6.73 \pm 6.54$ & $8.76 \pm 13.66$ & 0.657 \\
Spinopelvic realignment score & $0.73 \pm 0.98$ & $1.22 \pm 0.96$ & 0.026
\end{tabular}

PLK= proximal local kyphosis; $\mathrm{LL}=$ lumbar lordosis; $\mathrm{SS}=$ sacral slope; $\mathrm{PT}=$ pelvic tilting; $\mathrm{PI}=$ pelvic incidence; $\mathrm{SVA}=$ sagittal vertical axis; $\mathrm{CS}=$ cobb's scoliosis 
Table 4 Comparisons of postoperative radiographic parameters between two group

\begin{tabular}{lccc} 
Parameter & Study group & Control group & P values \\
\hline PLK & $5.33 \pm 8.51$ & $-9.13 \pm 13.97$ & $<0.001$ \\
LL & $25.52 \pm 11.71$ & $33.02 \pm 14.73$ & 0.031 \\
SS & $26.68 \pm 11.45$ & $28.88 \pm 11.05$ & 0.400 \\
PT & $24.93 \pm 10.13$ & $21.46 \pm 7.51$ & 0.296 \\
PI & $51.23 \pm 11.47$ & $50.34 \pm 11.39$ & 0.621 \\
PI-LL & $25.71 \pm 12.83$ & $17.32 \pm 12.64$ & 0.007 \\
SVA & $50.17 \pm 18.11$ & $40.32 \pm 12.56$ & 0.049 \\
CS & $5.06 \pm 5.54$ & $4.26 \pm 3.54$ & 0.973 \\
Spinopelvic realignment score & $1.13 \pm 0.89$ & $1.59 \pm 0.87$ & 0.045
\end{tabular}

$\mathrm{PLK}=$ proximal local kyphosis; $\mathrm{LL}=$ lumbar lordosis; $\mathrm{SS}=$ sacral slope; $\mathrm{PT}=$ pelvic tilting; $\mathrm{PI}=$ pelvic incidence; $\mathrm{SVA}=$ sagittal vertical axis; $\mathrm{CS}=$ cobb's scoliosis

Table 5 Patients' demographic data and clinical outcomes 


\begin{tabular}{|c|c|c|c|}
\hline Characteristic & $\begin{array}{l}\text { Study group } \\
\qquad(\mathrm{N}=24)\end{array}$ & $\begin{array}{l}\text { Control group } \\
\qquad(\mathrm{N}=72)\end{array}$ & $P$ values \\
\hline Age (years) & $71.17 \pm 4.45$ & $70.42 \pm 5.66$ & 0.557 \\
\hline \multicolumn{4}{|l|}{ Gender } \\
\hline Female & 20 & 60 & matched \\
\hline Male & 4 & 12 & \\
\hline \multicolumn{4}{|l|}{ Surgical segments } \\
\hline T10-L5 & 1 & 3 & \\
\hline T11-L5 & 1 & 3 & \\
\hline T12-L5 & 3 & 9 & matched \\
\hline L1-L5 & 3 & 9 & \\
\hline L2-L5 & 4 & 12 & \\
\hline T11-S1 & 1 & 3 & \\
\hline L1-S1 & 4 & 12 & \\
\hline L2-S1 & 3 & 9 & \\
\hline L3-S1 & 4 & 12 & \\
\hline T score & $-3.41 \pm 1.12$ & $-2.46 \pm 0.42$ & $<0.001$ \\
\hline BMI & $25.99 \pm 3.77$ & $26.56 \pm 3.51$ & 0.796 \\
\hline ASA score & $2.87 \pm 0.56$ & $2.63 \pm 0.64$ & 0.733 \\
\hline CCI & $1.75 \pm 0.90$ & $1.22 \pm 0.61$ & 0.002 \\
\hline \multicolumn{4}{|l|}{ Clinical outcome } \\
\hline Preoperative ODI (\%) & $53.95 \pm 20.60$ & $50.30 \pm 17.87$ & 0.406 \\
\hline Preoperative VAS (leg) & $6.33 \pm 1.94$ & $6.01 \pm 2.49$ & 0.570 \\
\hline \multicolumn{4}{|l|}{ Preoperative VAS } \\
\hline (back) & $7.04 \pm 2.21$ & $6.40 \pm 2.40$ & 0.254 \\
\hline \multicolumn{4}{|l|}{ Postoperative ODI (\%) } \\
\hline & $32.17 \pm 12.21$ & $20.90 \pm 17.94$ & $<0.001$ \\
\hline \multicolumn{4}{|l|}{ Postoperative VAS } \\
\hline (back) & $5.63 \pm 5.15$ & $2.42 \pm 2.33$ & $<0.001$ \\
\hline \multicolumn{4}{|l|}{ Postoperative VAS (leg) } \\
\hline & $2.33 \pm 2.37$ & $2.04 \pm 2.47$ & 0.613 \\
\hline
\end{tabular}


$\mathrm{BMI}=$ body mass index; $\mathrm{ASA}=$ American Society of Anesthesiologists; $\mathrm{CCI}=$ Charlson Comorbidity Index; ODI = Oswestry Disability Index; VAS = visual analogue scale

Figures

\section{Figure 1}

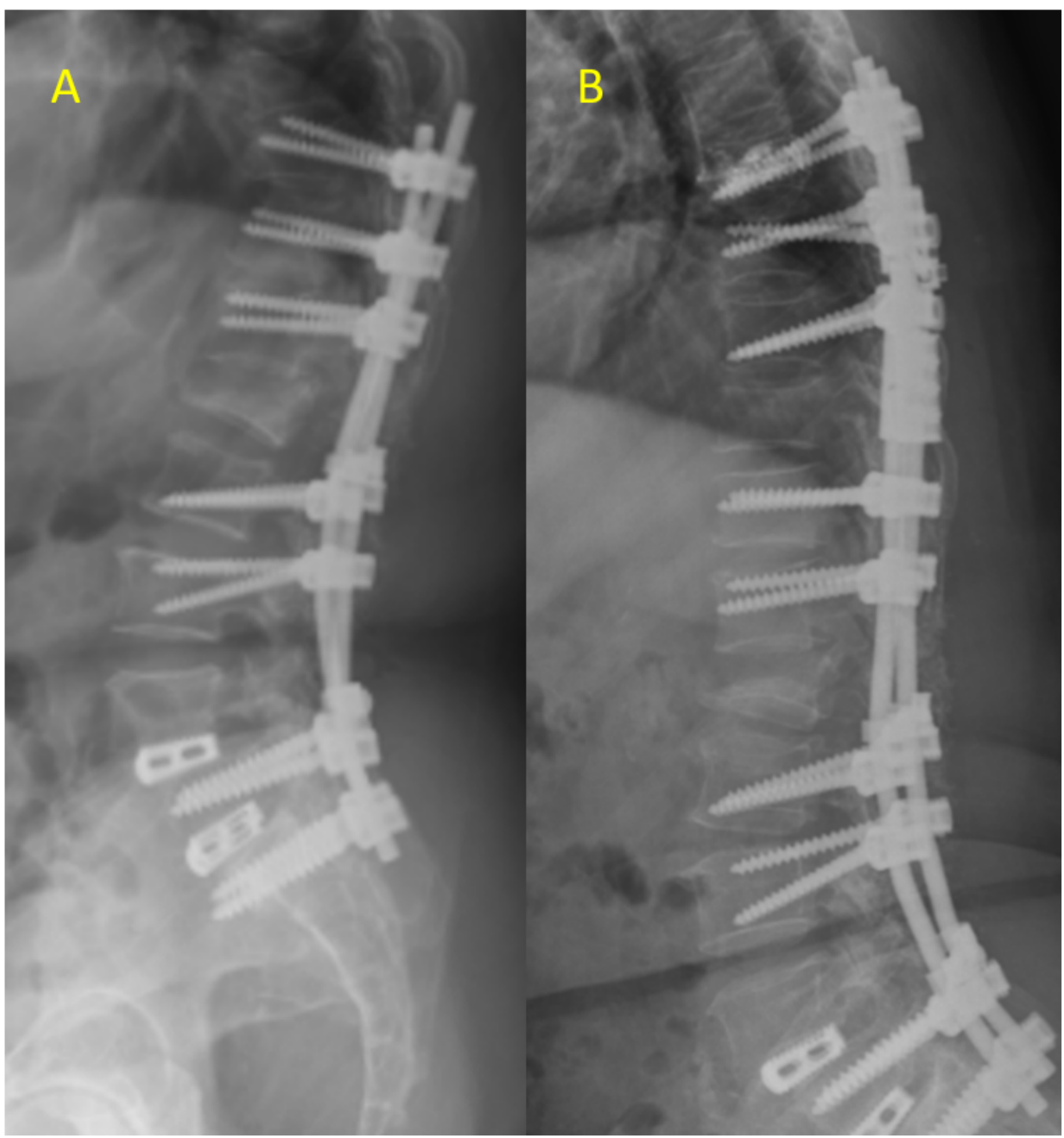


Figure 1

A case in the study group: (A) this patient suffered from fracture at upper instrumented vertebrae (T10), (B) extended instrumentation to T7 was performed.

\section{Figure 2}
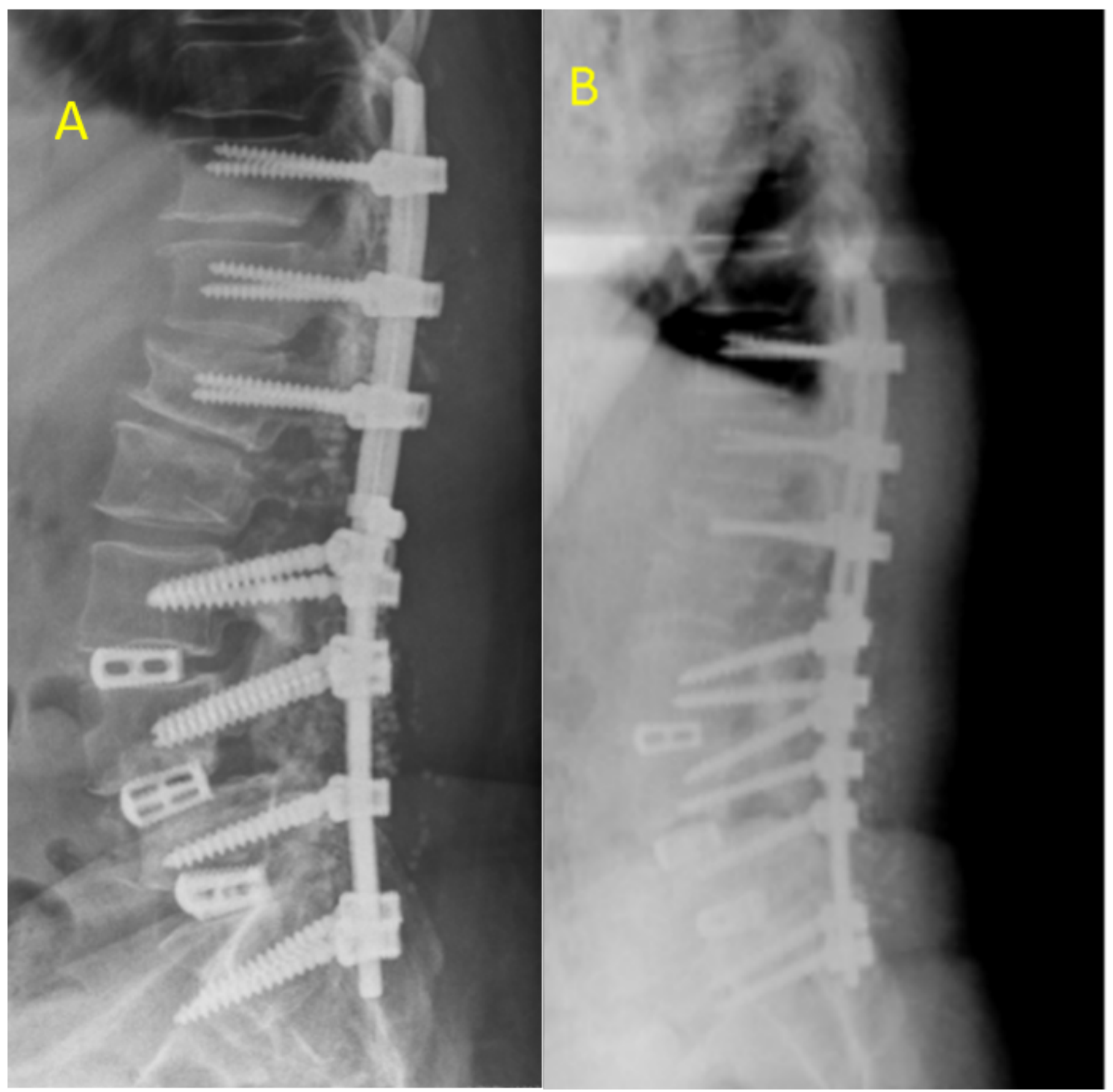

Figure 2 
A case in the control group: (A) immediately postoperative radiograph, (B) no proximal junctional failure developed at one-year follow-up radiograph. 